\title{
Reformar a Onu para Reconstruir o Multilateralismo
}

Antônio Celso Alves Pereiral

"Se quisermos que o sistema internacional se baseie em algo mais do que a força ou o poder, os Estados terão de regressar à instituição que criaram: As Nações Unidas".

Sérgio Vieira de Melo (Um dia antes de iniciar sua missão fatal no Iraque)

1) Diante do quadro de incertezas e de instabilidade política vigente na sociedade internacional contemporânea, situação que tem sua gênese nos paradoxos que emergiram do fim da Guerra Fria, como a consolidação do processo de globalização, o renascimento dos fundamentalismos no âmbito das religiões tradicionais, a exacerbação dos nacionalismos, o "novo"

\footnotetext{
${ }^{1}$ Professor dos Programas de Pós-Graduação em Ciência Política da UFRJ e em Direito da Faculdade de Direito de Campos. Rio de Janeiro. Presidente da Sociedade Brasileira de Direito Internacional. Ex-Reitor da UERJ.
} 
terrorismo, ${ }^{2}$ os sucessos das tecnologias da informação, a nova divisão internacional do trabalho e, sobretudo, o unilateralismo da política externa do Império norte-americano; o único meio racional para a construção de um diálogo eficaz na direção da paz e da cooperação entre os Estados, é a retomada do multilateralismo e, no contexto, o fortalecimento das Nações Unidas. "A recente guerra do Iraque e suas conseqüências até o presente momento - declara o chanceler brasileiro Celso Amorim -, demonstraram claramente os limites de enfoques unilaterais que recolocaram em evidência a necessidade de que a comunidade internacional seja sempre ouvida no equacionamento de crises que a afetam. Para isso a ONU foi criada. Por isso, continua a ser insubstituivel." ${ }^{3}$.

II) A crise de legitimidade que, há tempos, vem afetando a principal finalidade da ONU, ou seja, manter a paz e a segurança internacionais por meio do Conselho de Segurança, seu principal órgão, é agravada pela obsolescência de importantes dispositivos de sua Carta, que foi assinada em São Francisco, em 26 de junho de 1945, e que entrou em vigor em 24 de outubro do mesmo ano e que, por isso mesmo, refletia a realidade política, social, econômica

${ }^{2}$ O filósofo francês Paul Virilio, analisando a situação mundial, em artigo publicado na Folha de São Paulo, dia 4 de abril passado, afirma que a Guerra Fria foi substituída, em razão da escalada do terrorismo, pelo que ele chama de Pânico Frio, ou seja, o confronto em que o terror, seu protagonista, pode agir a qualquer hora, em quaiquer lugar. Segundo ele, o grande acidente do século XX não foi, como se chegou a propalar, o fim da história, mas o fim da geografia, pela compressão do espaço-tempo resultante do tremendo desenvolvimento das comunicações e dos transportes, tese, aliás, antes defendida pelo geógrafo inglês David Harvey, em 1989, sobre o que ele denominou o "o encolhimento do mundo". Segundo ainda Paul Virilio, tudo isso permitiu a emergência do exterminador; figura sinistra que está entre nós, e não é mais, simplesmente, um chefe de Estado". O grande chacinante é aquele que não leva em consideração a finitude do mundo. "No conflito dos mísseis cubanos - diz ele - em 196l, entre Kennedy e Kruschov, estávamos à beira do extermino. Hoje, qualquer um pode levar a essa situação. Basta colocar a bomba no lugar preciso, seja pela biologia, o vírus, a contaminação, a destruição de centrais nucleares ou outras tantas situações. Na dimensão suicida do novo terrorismo passamos da Guerra Fria para o Pấnico Frio - a cada momento um sentimento vem despertar o pânico do fim nas populações".

${ }^{3}$ EUA e o mundo, uma perspectiva brasileira. Artigo publicado na Folha de São Paulo, 12/10/2004, pág. A14. 
e estratégica dos primeiros tempos do pós-guerra. Nessa perspectiva, é importante observar, por exemplo, que alguns artigos da Carta devem ser simplesmente suprimidos, como o parágrafo $2^{\circ}$ do artigo 53 , na medida em que se refere a "Estado que, durante a Segunda Guerra Mundial foi inimigo de qualquer signatário da Carta". Japão, Alemanha e Itália principais "inimigos" a que faz menção o artigo 53, são hoje importantes membros das Nações Unidas. Da mesma forma, devem ser suprimidos os dispositivos que tratam do sistema internacional de tutela. Em 1994 o Conselho de Segurança pôs fim ao acordo de administração do último território sob tutela, as llhas do Pacífico - Palau -, que estavam sob a administração dos Estados Unidos. Contudo, o mais grave é a desatualização do Conselho de Segurança, idealizado pelos principais membros fundadores da ONU na Conferência de lalta, em fevereiro de 1945 - Estados Unidos, União Soviética e Reino Unido -. De início, é preciso considerar que o Conselho de Segurança foi construído seguindo os princípios do realismo político, isto é, na redução da política às relações de poder e à hierarquia entre os Estados, expressando uma composição autocrática que levava em conta as potências militares e econômicas da época e a reconstrução da ordem internacional após a derrota do nazifascismo.

Considerando, portanto, à época, a natureza da sociedade internacional vestfaliana, os fundadores da ONU buscaram construir um organismo que pudesse ser dotado de poderes que não confrontassem o princípio da soberania dos Estados, ${ }^{4}$ e viesse, não para revigorar a finada Sociedade das Nações, mas para substituí-la totalmente, estabelecendo, assim, um sistema de segurança coletiva cujo funcionamento só poderia se dar sob o acordo das grandes potências. Discutindo a natureza dos poderes das organizações intergovernamentais, Virally ${ }^{5}$

\footnotetext{
4 Ver artigo 20, parágrafo $1^{\circ}$ da Carta da ONU e a Resolução 2625 (XXV da Assembléia Geral), Declaração relativa aos princípio de direito internacional respeitantes às relações amigáveis e à cooperação dos Estados.

5 Virally, Michel. El devenir del derecho internacional. México: Fundo de Cultura Econômica, 1998, págs. 328/329
} 
assinala que estes estão limitados pela forma como se concretiza a distribuição do poder na sociedade internacional, e pelo princípio da soberania estatal. Assim, os poderes da organização internacional podem ser classificados em três tipos: o poder de debater, de discutir qualquer tema que envolva interesse dos Estados membros e da sociedade internacional como um todo; poder de decisão, que pode ser compulsório, se tomado pelo Conselho de Segurança, ai observado que não haverá aplicação desse poder, nos termos da exceção estabelecida pela Carta ao conferir o direito de veto aos Grandes, que têm assento permanente naquele órgão; e o poder de levar a cabo uma ação operacional, normalmente com o consentimento do Estado sobre cujo território tal iniciativa se desenrolará. A redação do artigo 27.3 da Carta da ONU aponta na direção do segundo tipo de poder, ou seja, o poder de decisão e controle. Dessa assertiva pode-se deduzir que os fundadores da ONU, ao criar o sistema de veto, se preocuparam em montar um dispositivo de coerção e de ação coletiva que, ao cabo, não é para ser empregado contra os Grandes.

Em vista disso, qualquer proposta de análise da Organização das Nações Unidas, deve, a priori, levar em conta que ela não é um Estado mundial, uma esfera de poder superior aos Estados, e, de forma alguma, a Assembléia Geral, é um legislativo mundial. Contudo, é preciso registrar que a Carta da ONU, ao estabelecer a supremacia do Conselho de Segurança em relação aos outros órgãos da instituição, assinala que as manifestações de vontade da Assembléia Geral materializam-se por meio de resoluções, que expressam apenas recomendações sem quaisquer condições impositivas. Porém, as decisões do Conselho de Segurança são de natureza obrigatória, e o seu não acatamento por parte de um Estado pode redundar em sanções determinadas pelo próprio Conselho de Segurança. A este, por sua vez, a Carta confere plenos poderes no que diz respeito às medidas necessárias para a manutenção da paz e da segurança internacionais, não the exigindo submeter suas decisões a qualquer outro órgão da ONU. Ao Conselho de Segurança são conferidos 
poderes de tal ordem que o Estatuto de Roma, que instituiu o Tribunal Penal Internacional, acabou por estabelecer, em seu artigo 16 , que o Conselho de Segurança pode solicitar a suspensão de processo instaurado nesse Tribunal, ou sustar a investigação de ilícitos tipificados no rol dos crimes internacionais mencionados no artigo $5^{\circ}$, todas as vezes que julgar que tais medidas sejam necessárias para a manutenção da paz da segurança internacionais. Diante da realidade derivada da composição do Conselho, isto é, do poder que a Carta da ONU confere aos membros permanentes, esta prerrogativa outorgada ao Conselho de Segurança é apontada como realista, ou seja, o Tribunal Penal Internacional não teria condições de funcionar, de forma efetiva, sem o apoio do Conselho de Segurança. Considerando que o Tribunal Penal Internacional é uma instituição judiciária internacional permanente, autônoma, dotada de personalidade jurídica internacional nos termos do seu Estatuto, não se pode deixar de mencionar que o citado artigo 16 atenta contra a independência e a autonomia dessa Corte. Apesar das contradições e, muitas vezes, da total inoperância do Conselho de Segurança em situações de grande relevância para a paz mundial, é válido destacar que o sistema de segurança coletiva das Nações Unidas representa um avanço em relação ao que fora estabelecido pela Liga das Nações, uma vez que é precisa e clara, na Carta da ONU - artigo 2 (4), a proibição da ameaça ou uso da força, o que não era contemplado de forma inequívoca no Pacto da extinta Liga das Nações. Contudo, como assinala Cançado Trindade, "as grandes potências nunca permitiram que esse sistema funcionasse bem, exercendo pressões que têm afetado negativamente o labor do Conselho de Segurança".

Considerando o exposto, fica claro que é urgente e necessária a reforma da Carta da ONU, especialmente dos seus dispositivos que regulamentam a composição, a competência e o sistema de voto no Conselho de Segurança, e, da mesma forma,

$\checkmark$ Cançado. Trinade, Antônio Augusto: Direito das Organizações Internacionais. Belo Horizonte: Livraria Del Rey Editora, 3 a edição, 2003, pág. 827. 
para revisar e estabelecer novas atribuições à Assembléia Geral e aos outros órgãos da instituição. Para que a Organização das Nações Unidas possa manter-se fiel ao realismo que norteou sua criação, para que possa se adaptar às realidades no tempo atual deve acelerar a sua própria reforma que, assevera o chanceler brasileiro Celso Amorim - "já está pronta como idéia, agora só tem se materializar". ${ }^{\text {? }}$

III) Nos primeiros anos da Guerra Fria, afirma o Professor Robert Wesson, da Boston University, ${ }^{8}$ a ONU foi muito útil aos interesses dos Estados Unidos. Assumia regularmente uma posição pró-norte-americana e anti-soviética, já que o bloco comunista contava com poucos votos e os Estados Unidos tinham o apoio de uma esmagadora maioria composta por Estados americanos e europeus. Nesse periodo, a ação da ONU foi relevante, na medida em que funcionou como importante e decisivo fórum onde exaustivas reuniões diplomáticas impediram a escalada para uma Terceira Guerra Mundial. Assim, os russos, em 1946, se viram obrigados a sair do Irã, mais precisamente do Azerbaidjão iraniano; na questão coreana os Estados Unidos foram buscar apoio na Assembléia Geral que, ao aprovar a resolução 377, denominada Uniting for Peace, em novembro de 1950, avocou a si competência para decidir matéria relativa à paz e à segurança internacionais, assunto de exclusiva competência do Conselho de Segurança, conforme determina o artigo 24 da Carta. Como se sabe, àquela altura, o Conselho de Segurança estava completamente paralisado por sucessivos vetos da União Soviética à proposta dos Estados Unidos de formação de tropa sob a bandeira da ONU para intervir na guerra civil coreana. A prerrogativa que a Assembléia Geral adquiriu com a Resolução Uniting for Peace foi posteriormente avocada quando da invasão da Hungria pelas tropas soviéticas, em novembro de 1956, na crise do Canal

\footnotetext{
7 Ver entrevista do ministro Celso Amorim na Folha de São Paulo, edição de 25/ 09/2004, pág. A 11.

${ }^{8}$ Wesson, G. Robert - Política Exterior Para Uma Nueva Era - Buenos Aires: Editorial Troquel SA, 1979 págs, 399/400.
} 
de Suez, também em 1956, e na questão de Katanga, no Congo, atual Zaire, em 1961. Não se pode deixar de registrar que, em 1962, a ONU, em vários aspectos, contribuiu para a saída do impasse gerado pela crise dos mísseis que os soviéticos pretendiam instalar em Cuba, incidente que quase levou as superpotências à guerra nuclear.

Com a entrada de dezenas de novos Estados oriundos do processo de descolonização, os Estados Unidos perderam o controle da Assembléia Geral e, a partir daí, não se interessaram mais pela Resolução 377 . Dominada por uma maioria de Estados de quase ou nenhum peso no sistema internacional, a Assembléia Geral tornou-se um espaço político de aberta oposição aos Estados Unidos. Agrupadas sob o controvertido rótulo de Terceiro Mundo, divididas em blocos como o dos não alinhados, o movimento neutralista, o Grupo dos 77, formado na I UNCTAD, as nações que saiam do estatuto colonial, em conseqüência da afirmação, pela própria ONU, do princípio da autodeterminação dos povos, aproveitavam o espaço democrático da Assembléia Geral para contestar e desafiar os Estados Unidos. A União Soviética, por sua vez, aproveitava o vento da transição, que impulsionava os movimentos de libertação nacional, para canalizar, em seu benefício, os interesses políticos e a luta dos povos submetidos às potências colonialistas. Basta lembrar que a resolução 1.514, votada na XV Assembléia Geral, em 14 de dezembro de 1960, a famosa Declaração sobre a Concessão de Independência aos Países e Povos Coloniais, nasceu de proposta da União Soviética.

A contestação aos Estados Unidos na Assembléia Geral, desde então, tornou-se uma constante na história das Nações Unidas. Foi na Assembléia Geral que os movimentos de libertação nacional encontraram apoio internacional para suas lutas pela independência e pela descolonização. Yasser Arafat, líder da Organização para a Libertação da Palestina, foi o primeiro representante de uma entidade não-governamental a discursar no plenário da Assembléia Geral das Nações Unidas, fato que se deu em 1974. Em 1988 o comandante da OLP pretendia, mais uma 
vez, participar da Assembléia Geral, mas o governo dos Estados Unidos proibiu sua entrada no país; a Assembléia Geral das Nações Unidas, naquele ano, foi transferida para Genebra, onde Arafat se fez ouvir. Deve-se observar que a Assembléia não é um órgão de funcionamento permanente. Reúne-se, anualmente, em sessões que têm início na terceira terça-feira do mês de setembro. A abertura das reuniões anuais da Assembléia Geral, por tradição, é feita pelo Brasil, o que vem ocorrendo desde as três primeiras Assembléias Gerais. Segundo Celso de Albuquerque Mello a tradição do Brasil de abrir as sessões anuais da Assembléia Geral tem origem no fato de que, nas três primeiras Assembléias Gerais, nenhuma das grandes potências manifestou a intenção de inaugurar o período de reuniões. O Brasil se ofereceu para proferir o discurso de abertura e, com isso, nasceu a tradição. ${ }^{9}$

Em 1947, diante dos vetos constantes impostos pelas grandes potências no Conselho de Segurança, e da conseqüente paralisia da ONU, criou-se, para funcionar por um ano, uma comissão interina com a finalidade de discutir os temas prementes relativos à paz e à segurança internacionais, num mundo dominado pela confrontação ideológica entre as duas superpotências. Denominada Pequena Assembléia, era formada por um representante de cada Estado membro, e deveria se reunir nos intervalos entre as sessões anuais da Assembléia Geral. Em 1948 foi prorrogada a sua existência e, em 1949, foil declarada permanente. Como não atingira seus objetivos, ou seja, pressionar os membros permanentes do Conselho de Segurança para que a Organização pudesse sair do impasse derivado dos continuados vetos, a Pequena Assembléia não mais foi convocada e caiu em desuso. ${ }^{10}$

É lamentável reconhecer que as Nações Unidas têm fracassado continuamente em sua função precípua de assegurar a paz e a segurança internacionais. Como exemplo recente, destaca-

${ }^{9}$ Ver, do autor, Curso de Direito Internacional Público. Volume I. Rio de Janeiro: Editora Renovar, 12a edição, 2000, pág. 661.

to Ver Mello, Celso. D. de Albuquerque, op. cit. pág. 697. 
se o papel marginal da instituição nas sucessivas crises - exlugoslávia, Ruanda, Somália, Sudão, e sua inoperância no Oriente Médio.

Com o fim da Guerra Fria e a forma como o Conselho de Segurança conduziu o processo de restauração da soberania do Kuweit na Guerra do Golfo, ${ }^{11}$ à primeira hora, configurou-se a percepção de que, finalmente, caminhava-se na direção de uma ordem internacional centrada no multilateralismo, numa tendência que indicava que a reestruturação do sistema internacional se daria com a fiel observância do direito internacional. Em discurso perante o Congresso dos Estados Unidos, o Presidente George Bush (pai), em 11 de setembro de 1990, anunciava o "advento de uma nova era, de um mundo no qual a primazia do Direito Internacional se imporia sobre a lei selva". Por sua vez, em 24 de setembro de 1990, o presidente da França, François Mitterrand, dirigindo-se à Assembléia Geral das Nações Unidas, reunida para a sua $45^{\mathrm{a}}$ sessão, proclamava que a reconstrução da nova ordem deveria se dar "sob o reinado do direito internacional". A coerência da nova ordem que se estruturava nos dias imediatos ao fim da Guerra do Golfo apontava, portanto, para o necessário fortalecimento da ONU, mediante a reforma do Conselho de Segurança-falava-se, à época, da inclusão da Alemanha e do Japão no Conselho, uma vez que estes dois países arcaram com boa parte dos gastos com a Guerra do Golfo $^{12}$ - e, ainda, da reformulação das instituições criadas pelos Acordos de Bretton Woods. Lamentavelmente, não foi o que

${ }^{11}$ Formou-se uma coalizão de 30 Estados, muitos deles muçulmanos, e uma guerra em que morreram $100 \mathrm{mil}$ soldados e 7 mil civis iraquianos, $30 \mathrm{mil}$ kuweitianos e 510 homens da coalizão.

12 "A forte pressão exercida pelos Estados Unidos para recuperar as despesas com a operação "Tempestade no Deserto" extraiu do Japão e da Alemanha US\$ 24 bilhões. Tal operação talvez tenha sido o motivo principal pelo qual o Japão e a Alemanha passaram a considerar como estratégicas suas candidaturas ao Conselho, para poder influir sobre suas decisões de intervenção e para evitar o constrangimento, para seus governos, de efetuar contribuições vultosas para financiar operações sobre as quais não tenha podido sequer opinar". Guimarães, Samuel Pinheiro. Quinhentos Anos de Periferia.: uma contribuição ao estudo da política internacional. Porto Alegre: Editora Contraponto, 2000, pág.109. 
aconteceu. Embora propondo um multilateralismo afirmativo, a administração Bill Clinton, sucessora do governo do primeiro Bush, não avançou nesse processo, e, em muitas ocasiões, adotou políticas que frontalmente ignoravam as $\mathrm{Nações} \mathrm{Unidas.} \mathrm{Com} \mathrm{a}$ eleição do presidente George W. Bush e os acontecimentos do 11 de setembro implementou-se nos Estados Unidos uma nova concepção de segurança nacional que, como é do conhecimento geral, enfatiza e ratifica a adoção de uma política externa unilateral, linha de ação externa que não leva em conta o recurso aos foros multilaterais de solução de controvérsias entre os Estados e que, de fato, já se manifestava antes mesmo dos ataques ao Pentágono e ao World Trade Center Diante do exposto, considerando apenas a ação da ONU no trato das questões relativas à segurança e à paz internacionais, resulta uma grande frustração com a Instituição. Contudo, é preciso levar em conta que, apesar disso, as Nações Unidas e seu sistema de organismos especializados desenvolveram e desenvolvem uma louvável atuação nos campos social, cultural e humanitário, circunstância que, de certa forma, absolve a Organização. Como já se disse, o processo de descolonização só foi possível pela ação capitaneada pela ONU. O esforço que o organismo e seu sistema fazem, por exemplo, no âmbito da Unesco para erradicar o analfabetismo e universalizar a educação básica e a educação superior nas regiões pobres do mundo, deve ser devidamente destacado. Por outro lado, a ONU, por meio da Organização Mundial da Saúde, empenha-se na luta mundial para prevenção e tratamento da Aids e nas campanhas de erradicação de endemias nas regiões pobres do mundo, ações de natureza social da maior relevância, às quais podemos acrescentar a defesa dos direitos do trabalhador pela Organização Internacional do Trabalho, a proteção de 17 milhões de refugiados em todos os continentes pelo Alto Comissariado das Nações Unidas para Refugiados - ACNUR - e, da mesma forma, as ações do Alto Comissariado para os Direitos Humanos. Deve-se ressaltar que na segunda metade do século passado, após a promulgação da Declaração Universal dos Direitos do Homem, as Nações 
Unidas conseguiram aprovar, além da Carta Internacional dos Direitos Humanos, inúmeras convenções internacionais versando sobre a proteção geral e particularizada desses direitos. Outro ponto alto da atuação das agências das Nações Unidas está na atividade normativa, reguladora e controladora empreendida pelas Organizações Marítima e de Aviação Civil Internacional para a segurança e o desenvolvimento dos transportes em âmbito internacional.

IV) Voltando à tese sobre o fortalecimento das Nações Unidas, de imediato, pode-se concluir que a reforma do Conselho de Segurança é, como já se falou, urgente e absolutamente necessária para assegurar maior legitimidade e renovar a confiança da opinião pública mundial na instituição. Há hoje uma nova realidade política, estratégica e econômica no mundo. Ao tempo em que se constituiu o Conselho de Segurança, a ONU era composta por 51 membros e, atualmente, conta com 19l Estados. O presidente Jacques Chirac, um dos mais contundentes defensores do fortalecimento das organizações multilaterais, afirma que o atual modelo de organização internacional expresso na Carta da ONU não permite à instituição assumir tarefas de um projeto multilateral de paz e segurança no mundo. Em dezembro de 2003, instalou-se em Nova York uma comissão mundial de alto nível, designada pelo Secretário-Geral Kofi Annan, para tratar da reforma. A Comissão, presidida por Anand Panyarachum, antigo primeiroministro da Tailândia, é composta por 16 personalidades de 16 países, dentre as quais o embaixador brasileiro João Clemente Baena Soares. Ela terá um ano para apresentar ao SecretárioGeral um projeto de reforma a ser submetido ao Conselho de Segurança e à Assembléia Geral. O objeto central da reforma será o Conselho de Segurança. Todas as sugestões que até agora têm sido apresentadas para reformar o Conselho focalizam a questão básica do número de componentes do mesmo, especialmente o quadro de membros permanentes, e, ao lado disso, o sistema de veto. 
De acordo com os dispositivos em vigor, são quinze os Estados que compõem o Conselho de Segurança: cinco permanentes e dez não permanentes. O Brasil atualmente é membro não permanente do Conselho e aparece como o país que mais vezes lá esteve nessa qualidade: nove vezes. As propostas de reforma do Conselho são variadas. Os norteamericanos, em princípio, aceitam discutir a reforma partindo da possibilidade da entrada do Japão e da Alemanha como membros permanentes, e mais três Estados escolhidos por critério geográfico e peso regional, ou seja, um da América Latina, um da Ásia e outro da África. Não aceitam a supressão do veto e adiantam que somente darão a palavra final sobre o assunto, ou seja, se os novos membros permanentes teriam ou não direito a veto, ou se ficariam como membros intermediários entre os membros permanentes fundadores e os não-permanentes, quanto estiver decidido quais os Estados do critério geográfico entrariam para o Conselho de Segurança. Vale registrar que são candidatos, pelo critério regional e por representação dos países emergentes, o Brasil, a África do Sul, e a Índia. Pela América Latina, acreditase que a Argentina e o México disputarão com o Brasil. A Indonésia e o Paquistão, pela Ásia, tentarão ganhar a vaga à Índia. Egito e Nigéria, certamente, concorrerão com a África do Sul.

A proposta italiana é no sentido de aumentar apenas o número de membros não permanentes, isto é, dos 10 atuais, para um total de 25 a 30 membros, que teriam mandatos de 6 anos, observados novos critérios de rodízio a serem estabelecidos. Contudo, os italianos sustentam que os novos membros não permanentes seriam escolhidos conforme sua capacidade de contribuição financeira e de participação em missões das Nações Unidas.

Conforme recenté manifestação de Jack Straw, ministro do Exterior da Grã-Bretanha, ${ }^{13}$ seu governo é pela ampliação do Conselho de Segurança, isto é, passar dos 15 membros atuais

13 Ver O Globo, edịção de 24/10/2004, pág. 14. 
para um total de 24 , incluindo, entre os membros permanentes, Brasil, Índia, Japão e Alemanha.

A posição brasileira é no sentido de ampliar o número total de membros do Conselho para 20 ou, preferivelmente, para 25 . Este número traria a vantagem de proporcionar uma divisão do Conselho entre países ricos e emergentes, o que seria ideal para ampliar o diálogo entre os dois grupos. Quanto aos membros permanentes a proposta brasileira defende a ampliação do quadro, não aceitando que os novos membros permanentes fiquem em situação que os leve a serem classificados como membros de segunda categoria, por exemplo, sem o direito de veto. Nessa perspectiva, vitoriosa a tese de criação de assentos permanentes sem direito a veto, o Conselho de Segurança passaria a ter três classes de membros: permanentes com direito a veto, permanente sem direito a veto, e não permanentes. Nosso governo entende que se o direito de veto continuar, deverá ser estendido aos novos membros permanentes.

O Brasil, por sua condição de potência regional, pela força de sua economia, tem todas as condições para aspirar um assento permanente, com direito a veto, no Conselho de Segurança. Contudo, é forte dentro do país a corrente de opinião que considera prejudicial a admissão do Brasil como membro permanente pleno no Conselho de Segurança. Para alguns, a intenção brasileira seria apenas uma busca de prestígio internacional, sem conseqüências práticas para o país. Outros argumentam que o Brasil não teria condições econômicas e militares para assumir compromissos vultosos em matéria de segurança internacional. Não procede tal assertiva. Como lembra o ministro Celso Amorim, "o Brasil não terá de aumentar sua contribuição às Nações Unidas, hoje por volta de 28 milhões de dólares - cerca de 1,5\% do Orçamento da instituição e acima do valor pago pela Rússia e pela China, que são membros permanentes". ${ }^{14}$ É oportuno salientar que o Brasil, quando da criação da ONU, por indicação do Presidente Roosevelt, chegou a ser cogitado para membro permanente do Conselho de

${ }^{14}$ Entrevista à Folha de São Paulo, edição de 25/09/2004, pág. A 11. 
Segurança. Além disso, sempre que solicitado, atendeu aos apelos das Nações Unidas para participar de operações de paz ${ }^{15}$, como aconteceu em Suez, no Oriente Médio, em Angola, no Timor e agora no Haiti. O ingresso no Conselho de Segurança como membro permanente pleno permitiria ao Brasil uma real inserção no grande jogo político mundial e, com poder de veto, o pais teria maiores condições de defender seus interesses no cenário internacional. Como assegura Samuel Pinheiro Guimarães, este é o momento oportuno para o Brasil pleitear seu assento permanente no Conselho, pois seria muito difícil obter os dois terços de votos na Assembléia Geral, exigidos pelo artigo 108 da Carta, para aprovar emenda que incluiria apenas o Japão e a Alemanha, deixando de fora Estados emergentes de real peso econômico e político em seus espaços regionais.

A proposta alemã é praticamente idêntica à brasileira. Vale acrescentar que o Japão e a Alemanha só admitem suas inclusões no Conselho de Segurança como membros permanentes plenos, portanto, com direito a veto.

A polêmica questão do veto suscita as mais variadas sugestões. São inúmeras as manifestações pela total supressão desse mecanismo. Algumas propostas aparecem indicando que o veto, ao contrário do que acontece hoje, só se aplicaria em questões que seriam, pela reforma, claramente tipificadas no corpo da Carta. Para uma melhor compreensão do problema, deve-se esclarecer que, atualmente, as matérias submetidas à votação no Conselho de Segurança são classificadas em duas categorias: processuais e não processuais. As questões processuais, para serem aprovadas, devem receber o voto afirmativo de, no mínimo, nove de quaisquer dos quinze membros; as classificadas como não processuais requerem, para a sua aprovação, o voto afirmativo de, no mínimo, nove dos membros do Conselho, incluídos os votos afirmativos de todos os membros permanentes. O voto negativo de qualquer dos membros permanentes transforma-se em veto.

\footnotetext{
${ }^{15}$ Atualmente estão em atividade, em várias partes do mundo, 14 missões de paz das Nações Unidas.
} 
Deve-se destacar ainda que a Carta das Nações Unidas, complicando a questão, não estabelece quais são as matérias processuais e não processuais. Assim, para ser classificada, a matéria é posta em votação que determinará sua natureza. Esta votação preliminar é considerada matéria importante, propiciando, assim, o aparecimento do chamado duplo veto.

Explica Samuel Pinheiro Guimarães que países com visão mais realista do problema, "consideram que o próprio direito de veto torna impossível a sua eliminação ou mesmo sua restrição. Assim, a inclusão da Alemanha e do Japão cria a oportunidade única de admitir uns poucos países periféricos no Conselho e assim, não sendo possível eliminar, a solução seria estender o direito de veto a esses novos membros, identificados com os interesses da periferia". ${ }^{16}$

Existem outras propostas, classificadas por Pinheiro Guimarães como "idealistas e obstrucionistas", patrocinadas por Estados que não teriam condições de ingressar no Conselho como membros permanentes. Estes defendem que o ideal seria a inclusão exclusiva do Japão e da Alemanha como membros permanentes plenos, portanto com direito a veto, e, ao lado disso, a criação de assentos regionais rotativos, o aumento do número de membros não permanentes e, por fim, a criação de uma outra categoria de membros: os permanentes sem direito de veto.

Há outra questão importante, relativa ao Conselho de Segurança, que deve ser objeto de discussão na reforma que se anuncia. Trata-se da necessidade do estabelecimento de mecanismos de controle da legalidade dos atos praticados pelo Conselho. Segundo o antigo Secretário de Estado dos Estados Unidos, John Foster Dulles, "o Conselho de Segurança não é um órgão que simplesmente aplica o direito internacional. Ele é por si mesmo um direito". Portanto, seus atos não guardariam a obrigação de estarem conforme a própria Carta da ONU e nem mesmo ao direito internacional. Lembra Celso Mello que Kelsen considerava

${ }^{16}$ Guimarães, Samuel Pinheiro. Quinhentos Anos de Periferia. Porto Alegre: Contraponto/Editora Universidade Federal do Rio Grande do Sul, 2000. pág.111 
que para manter a paz o Conselho de Segurança podia aprovar resolução que não estivesse conforme o Direito Internacional. ${ }^{17}$ Esta questão vem sendo objeto de discussão des de a criação da ONU. Não há, portanto, um órgão jurídico internacional competente para exercer o controle da legalidade dos atos do Conselho de Segurança. O tema é, pois, da maior importância e deverá fazer parte da agenda que discutirá a reforma das Nações Unidas. Como bem assinala Cançado Trindade "com o passar dos anos, a necessidade desse controle de legalidade tem se tornado manifesta, sobretudo à medida em que as Nações Unidas ocupam um espaço cada vez maior em um cenário internacional marcado por novos e intensos conflitos, inclusive internos". ${ }^{18}$ Assim, entendese que a sugestão mais adequada nessa matéria seria ampliar a competência da Corte Internacional de Justiça e encarregá-la do controle. Alguns autores admitem que esta possibilidade enfraqueceria o Conselho de Segurança. Conforme Celso de Albuquerque Mello, "um controle a priori seria um entrave à sua atuação. Poderia existir um controle a posteriori se a ação fosse ilegal daria margem a uma reparação. Acresce que a Corte tem afastado as denominadas questões políticas que não podem ser solucionadas pelo direito". ${ }^{19}$ Os limites desta exposição não permitem discutir adequadamente esta importante questão jurídica. Contudo, é bom registrar que o problema esteve em pauta na Corte Internacional de Justiça no caso Lockerbie, ocasião em que este Tribunal entendeu que as decisões do Conselho de Segurança, tomadas com fundamento no Capítulo VII da Carta, não podem ser reformadas por nenhuma Corte, uma vez que as obrigações decorrentes de resoluções obrigatórias do Conselho de Segurança, em razão do que estabelece o artigo 103 da Carta da ONU, são superiores a qualquer tratado firmado pelos Estados. Esta referência ao artigo 103 se deu em razão da invocação pela Líbia, perante a Corte Internacional de Justiça, da Convenção de Montreal

\footnotetext{
17 Op. cit. pág. 618.

${ }^{38}$ Direito das Organizações Internacionais, pág. 841.

${ }^{19} \mathrm{Cf}$. Celso D. de Albuquerque Mello, op. cit. págs. 617/618.
} 
de 1971 sobre a Supressão de Atos llícitos contra a Segurança da Aviação Civil, para sustentar o pedido de medidas conservatórias que the garantissem o direito de julgar em seu território os indiciados no caso da explosão do avião da $\operatorname{Pan} A m$ quando sobrevoava Lockerbie, na Escócia, no dia 21 de dezembro de 1988. Em 1991 a Grã-Bretanha e o Estados Unidos solicitaram a extradição dos responsáveis pelo crime - dois indivíduos de nacionalidade líbia - para serem processados. O governo líbio silenciou-se diante do pedido. Os interessados na extradição recorreram ao Conselho de Segurança e este, mediante resolução com base no Capítulo VI da Carta ${ }^{20}$, ordenou ao governo Khadafi que se manifestasse sobre o pedido de extradição. Diante disso, a Líbia, com base na citada Convenção de Montreal, recorreu à Corte solicitando as medidas conservatórias já mencionadas, uma vez que dispositivos dessa Convenção facultam ao Estado julgar ou extraditar os indiciados. Contudo, em 31 de março de 1992, o Conselho de Segurança aprovou uma nova resolução ${ }^{21}$ sobre o assunto, desta feita, com fundamento no Capítulo VII da Carta, ordenando à Líbia que concedesse a extradição dos dois acusados. A Corte Internacional de Justiça, após exame e julgamento das alegações da Libia, em 14 de abril de 1992, negou o pedido. Esta questão acabou sendo resolvida por acordo entre os Estados Unidos, Grã-Bretanha e Libia. ${ }^{22}$

Em relação à Assembléia Geral sua reforma deveria avançar no sentido de revitalizá-la como foro universal e democrático, onde questões que afetam a humanidade possam ser discutidas e encaminhadas às soluções pertinentes. Há, nessa direção, proposta de instituição de um Fórum Anual da Sociedade

${ }^{20}$ Resolução 731 de 21 de janeiro de 1992.

${ }^{21}$ Resolução 748 de 31 de março de 1992. Sobre o tema ver Cançado Trindade, Direito das Organizações Internacionais, págs. 823/853.

${ }^{22}$ Ver Bedjaoui, Mohammed. Nuevo Orden Mundial y Controle de Legalidad de los Actos del Consejo de Seguridad: Bilbao: Instituto Vasco de Adminstración Pública, 1995. Ver também do mesmo autor Les Relations entre la Cour Internationale de Justice et les Autres Organes Principaux des Nations Unies. In : Boutros Boutros-Ghali - Amicorum Discipulorumque Liber. Bruxelles: Bruylant, 1999, págs. $175 / 226$ 


\section{4}

Civil Internacional, que seria composto por representantes de organizações não-governamentais acreditadas junto à Assembléia Geral. Assim, reuniões como as que se sucedem em Davos e em Porto Alegre deveriam se dar no âmbito da Assembléia Geral. Segundo a Fundação Olof Palme, a reforma da Assembléia Geral deveria considerar a realização constante de sessões temáticas, o exercício de uma efetiva autoridade orçamentária e a modernização de sua agenda e de seus procedimentos.

Sobre o Conselho Econômico e Social existem propostas no sentido de transformá-lo em Conselho de Segurança Econômica, nele sendo incluídos os organismos financeiros e comerciais internacionais, que passariam à categoria de órgãos da estrutura das Nações Unidas e não mais instituições do sistema capitaneado pela Organização.

Em relação ao Secretariado a reforma poderia emendar o artigo 96 da Carta da ONU para incluir, de forma expressa e clara, o Secretariado entre os órgãos das Nações Unidas que podem solicitar opinião consultiva à Corte Internacional de Justiça, considerando a relação complementar existente entre o Conselho de Segurança e o Secretário-Geral.

A ONU, desde a sua fundação, vem enfrentando graves problemas orçamentários. O grave dessa questão é que quase todos os Estados membros, inclusive os ricos, não saldam suas contribuições em dia. Nesse contexto, deve-se ainda considerar que dois terços dos países membros contribuem com menos de $1 \%$ para o organismo, e, quase sempre, estão inadimplentes. Os Estados da União Européia, em seu conjunto, são os maiores contribuintes para o orçamento corrente da ONU e para as operações de manutenção dapaz.

V) A reforma das Nações Unidas, como foi dito, é imprescindivel e inadiável para a continuidade desta importantíssima instituição. A atual composição do Conselho de Segurança configura uma estrutura anacrônica e oligárquica que está longe de refletir a realidade política do mundo atual. Diante do que se passa no mundo atualmente, da ameaça constante do terrorismo transnacionalizado, 
da natureza do processo de globalização, da realidade da integração cultural, que é dinamizada pelas tecnologias da informação, enfim, da universalização de todas as atividades humanas, a Organização das Nações Unidas deve dotar-se de mecanismos modernos que Ihe permita atender com eficiência e legitimidade todas as questões que the forem postas pelas forças que compõem a atual sociedade internacional. Nessa direção a reforma deve levar na devida conta a crescente capacidade da sociedade civil internacional de contribuir para a governabilidade mundial.

As emendas à Carta, para serem aprovadas, devem obedecer ao que dispõe o seu artigo 108. Embora o texto deste artigo não confira aos membros permanentes o direito de vetar emendas, estas só entram em vigor se aprovadas por $2 / 3$ da Assembléia Geral e ratificadas por $2 / 3$ dos membros das Nações Unidas, inclusive todos os membros permanentes do Conselho de Segurança, exigência que, desta forma, acaba permitindo o veto. $A$ revisão da Carta está regulada pelo artigo 109 e deve se processar no âmbito de uma Conferência Geral da Revisão. A entrada em vigor dos artigos revistos se dará de forma semelhante ao que a Carta exige para entrada em vigor das emendas.

Diante do exposto, resta-nos aguardar o relatório que a Comissão de Alto Nível designada para estudar e apresentar propostas de reforma das Nações Unidas deverá apresentar em dezembro do corrente ano de 2004 e, posteriormente, conhecer a posição dos cinco membros permanentes sobre a viabilidade das sugestões de reforma apresentadas. . "A necessidade de as atuarem de maneira harmônica, para a superação dos problemas mais graves - afirma o embaixador José Mauríco Bustani - requer a recuperação e o fortalecimento do multilateralismo como elemento ordenador das relações internacionais. Tal processo exige a renovação do contpromisso de todos com as regras do direito internacional e com a integridade das instituições multilaterais, como as Nações Unidas", ${ }^{23}$

${ }^{23}$ Mitos e desafios na política externa. Artigo publicado na "Folha de São Paulo", 09/09/2004, pág. A - 3 . 